\title{
Geometric characterization of soil structure through unconventional analytical tools
}

\author{
Chien Ling Tseng,*, Marlene Cristina Alves ${ }^{\mathrm{b}}$, Débora Marcondes Bastos Pereira Milori ${ }^{\mathrm{c}}$, \\ Silvio Crestana ${ }^{\mathrm{c}}$ \\ a University of São Paulo, "São Carlos School of Engineering", 400 Avenida Trabalhador São-carlense, CEP: 13566-590 São Carlos, São Paulo, Brazil \\ ${ }^{\mathrm{b}}$ Universidade Estadual Paulista, "Rural Engineering and Soil", 56 Avenida Brasil, Centro, CEP: 15385-000 Ilha Solteira, São Paulo, Brazil \\ ${ }^{\mathrm{c}}$ Embrapa Instrumentation, 1452, Rua XV de Novembro, CEP: 13560-970, São Carlos, São Paulo, Brazil
}

\section{A R T I C L E I N F O}

\section{Keywords:}

Microtomography

Porosity

Shape factor

Fractal dimension

Lacunarity

Tropical soil

\begin{abstract}
A B S T R A C T
Soil structure is essential for soil function and environmental quality. Therefore, adequate evaluation of management systems is essential to ensure the preservation and regeneration of soil structure. Techniques such as Xray microtomography and automated soil particle size analysis based on gamma-ray attenuation provide rapid quantification of soil physical properties and allow for the evaluation of soil structure. The aim of this study is to determine soil physical parameters using unconventional analytical tools to characterize and evaluate the geometric characteristics of soils with different structures at high accuracy. Soil samples extracted from the UNESP experimental farm (Brazil) were separated into two different management groups according to their textural similarity. The following results were obtained from the analysis: 1) Microtomography can be used to extract soil porosity, including soil microporosity. 2) The shape factor indicates the geometric organization of the soil structure, which is relevant and valid for evaluating the degree of soil degradation. 3) The fractal dimension is related to the soil particle and aggregate size distribution but was not sufficient for describing the soil geometric properties when used alone. 4) Coupling the fractal dimension with the lacunarity provides an important tool for estimating the soil structure. Finally, the application of the physical parameters from the unconventional method provided new insights for understanding soil geometric structure, which can support future investigations of flow phenomena in the soil.
\end{abstract}

\section{Introduction}

Adequate soil management is essential for guaranteeing agricultural production and for promoting environmentally and socio-economically sustainable development around the world. Soon, the preservation and regeneration of soil structure will become essential for maintaining important soil functions and for securing environmental quality. However, one of the current challenges in the study of soil structure is the lack of knowledge on how to non-destructively and reliably evaluate soil physical parameters, including soil structure, which is influenced by management practices and intensity.

Soil physical parameters are usually measured to obtain a better understanding of soil processes, such as the effects of tillage on soil structure (Reynolds et al., 2009). Using visual analysis, Carducci et al. (2016) assessed how the structure of an Oxisol changed as a consequence of management and validated their findings by X-ray Computerized Tomography (CT) scanning of undisturbed soil samples. Pires et al. (2017) explored diverse tools to quantify pore system differences between conventional and no-till management systems. Likewise, Naveed et al. (2016) quantified vertical stress transmission in an arable topsoil and determined compaction-induced soil structure by applying $\mathrm{X}$-ray CT.

For the first time, a set of unconventional analytical tools was used concomitantly to investigate the geometric structure of tropical soils under different types of management. We selected several unconventional techniques and methods to determine the most pertinent analysis options. These techniques and methods include an automated soil particle size analyzer (Naime et al., 2001), X-ray CT and digital image processing (Crestana et al., 1985, Passoni et al., 2014). We mainly chose these methods and techniques based on the concept that the soil texture directly affects the soil structure. In addition, CHNS/O Elemental Analysis and Laser Induced Fluorescence Spectroscopy (LIFS) (Milori et al., 2006 and Senesi et al., 2016) were introduced to supplement the discussion.

\footnotetext{
* Corresponding author.

E-mail addresses: chienlt86@sc.usp.br (C.L. Tseng), mcalves@agr.feis.unesp.br (M.C. Alves), debora.milori@embrapa.br (D.M.B.P. Milori), silvio.crestana@embrapa.br (S. Crestana).
} 
Tseng et al. (2018) focused on a methodological evaluation of soil structural quality using one representative image. Tomographic images were used to qualitatively evaluate the regeneration process of a Brazilian Oxisol under different types of management by Marchini et al. (2015). Vaz et al. (2011) quantified the porosity and the pore size distribution of two Brazilian Oxisols, resulting in important information for establishing appropriate scanning parameters for these soils. Beraldo et al. (2014) also applied a tomographic method to evaluate the porosity of three soil management systems and verified that their method could be used to obtain information at the macropore scale.

For this study, we used an elemental analyzer and a LIFS system to calculate the soil carbon (C) content and humification index of soil organic matter (Milori et al., 2006 and Senesi et al., 2016) as indicators of the resistance of the soil to microbial decomposition. The humification index can be low if the soil organic matter is protected inside aggregates; the $\mathrm{C}$ content of macroaggregates is greater than that of microaggregates (Six et al., 2000).

With respect to shape factors or pore form, Passoni et al. (2014) applied ImageJ software to characterize Oxisols from the southeastern region of Brazil and successfully demonstrated the possibility of using this software to identify the characteristics of pores in tropical soils. Munkholm et al. (2016) confirmed that long-term management of the soil alters both its aggregate form and pore characteristics by using CT scanning and tensile strength measurements.

The fractal dimension is an indicator of the complex geometrical structure of an object, e.g., the soil structure; thus, the fractal dimension can be used to quantify small-scale soil structure data obtained with Xray CT (Zeng et al., 1996). Then, the fractal dimension can be used to describe the soil physical properties, model soil physical processes and quantify soil spatial variability (Perfect and Kay, 1995). In this study, the fractal dimension was correlated with the soil texture (granulometry), which were obtained using X-ray CT and an automated soil particle size analyzer, respectively.

Although the lacunarity concept was initially conceived to describe fractal properties, it can be extended to other natural spatial patterns without any restrictions (Plotnick et al., 1996; Allain and Cloitre, 1991). In other words, the lacunarity curve corresponds to the degree of spatial heterogeneity and the self-similar characteristics of the soil texture in practical terms. This concept applies regardless of whether the soil texture is fractal or random, i.e., the presence or absence of a geometric pattern. The work of Monreal et al. (2013) is particularly interesting because these authors applied the concept of lacunarity to investigate the spatial distribution of pedotaxa in Europe. In Roy and Perfect (2014), analytical and digital tools were used to investigate lacunarity and its influences on flow and transport processes within grayscale representations of soil aggregates. In another study, Martínez et al. (2017) analyzed lacunarity in 3D images of soil columns to characterize their macropore space geometry. Additionally, when the lacunarity (L) decreases toward $\ln [\mathrm{L}(\mathrm{r})]=0$ and remains constant, the box or cube size ( $r$ ) is approached as the representative elementary volume (REV) (Luo and Lin, 2009).

The aim of this study is to determine soil physical parameters using unconventional analytical tools to characterize and evaluate the geometric characteristics of soils with different structures at high accuracy.

\section{Material and methods}

\subsection{Experimental sites}

The soil samples were obtained at the Fazenda de Ensino e Pesquisa da Universidade Estadual Paulista "Júlio de Mesquita Filho" (UNESP), Teaching and Research Farm of the Paulista State University "Júlio de Mesquita Filho", on the Ilha Solteira campus in the city of Selvíria (Mato Grosso do Sul State - Brazil). This farm is located on the banks of the Paraná River $\left(22^{\circ} 22^{\prime} \mathrm{S}\right.$ and $\left.51^{\circ} 22^{\prime} \mathrm{W}\right)$. In the 1960 s, at the beginning of the construction of the hydroelectric power dam in Ilha
Solteira (São Paulo State), an 8.6-m-thick soil layer was sampled from the original soil surface to prepare and construct the dam's foundation. Since 1969, subsoil containing B horizon material has remained exposed at the surface and has shown serious stages of superficial compaction and a low presence of vegetation. The soil in the experimental area is a Brazilian Oxisol characterized by advanced stages of weathering and an acidic $\mathrm{pH}$ that is typical for equatorial and tropical regions (Embrapa Solos, 2013).

\subsection{Soil sampling description}

In this study, soil samples were collected at a depth of $0-10 \mathrm{~cm}$ in the form of undisturbed blocks $(30 \mathrm{~cm} \times 30 \mathrm{~cm} \times 10 \mathrm{~cm})$ from areas under six different types of management, (i.e., with different soil geometric structural statuses). The samples were preserved at ambient temperatures and then one subsample ( $8 \mathrm{~mm}$ diameter $\mathrm{x} 12 \mathrm{~mm}$ height) was obtained from each block by using an acrylic tube. Next, the subsamples were dried at $105^{\circ} \mathrm{C}$ for $48 \mathrm{~h}$. Upon their collection, the samples were divided into two groups based on their textural similarity as follows. Group I: 1) NF - soil from native forest (control); 2) RS - regenerated soil, formed by applying green manure to the soil over seven years, from 1992 to 1999, followed by cultivation with Brachiaria decumbens; 3) G - regenerating soil with Astronium fraxinifolium (Gonçaloalves) + Brachiaria decumbens + domestic sewage sludge and without heavy metal contamination from the Araçatuba Sewage Treatment Plant; and 4) D - degraded soil (remaining soil from the construction of the hydroelectric power plant). Group II: 5) RP - regenerating pasture soil and 6) DP - degraded pasture soil. The soil from the NF was considered to be a reference for comparison in both groups.

\subsection{Equipment}

Four analytical apparatuses were used in this study: i) an Embrapa Instrumentation homemade automated soil particle size analyzer; ii) a commercial X-ray microtomograph, model 1172 - Skyscan/Bruker (Kontich, Antwerp, Belgium); iii) a commercial CHNS/O elemental analyzer, model 2400 - PerkinElmer (Waltham, MA, USA) and iv) an Embrapa Instrumentation homemade LIFS (Laser Induced Fluorescence Spectroscopy). With these devices, sets of physical parameters were derived for each management system.

\subsubsection{Automated soil particle size analyzer}

The automated soil particle size analyzer is an instrument developed by Embrapa Instrumentation - São Carlos. It uses gamma-ray attenuation based on the modified Beer-Lambert Law and Stoke's Law to quickly determine particle size distribution, soil texture (granulometry), particle density, the water retention curve and the $S$ index for soil (Vaz et al., 1992; Naime et al., 2001).

For pretreatment, the soil samples were dried in an oven at $105^{\circ} \mathrm{C}$ for $24 \mathrm{~h}$ and passed through a $1.5 \mathrm{~mm}$ mesh sieve to remove gravel and any remaining plant roots. The soil organic matter not was oxidized with $\mathrm{H}_{2} \mathrm{O}_{2}$. Next, the mass attenuation coefficients $\left(\mu_{\mathrm{m}}\right)$ (Eq. 1 ) were determined for all the samples. Subsequently, $40 \mathrm{~g}$ of soil was mixed with $10 \mathrm{ml}$ of sodium hydroxide solution $(\mathrm{NaOH})$ and distilled water in a Wagner type shaker for $16 \mathrm{~h}$ to ensure that the solutes were uniformly dissolved in the water. Finally, the solution was transferred to a cuvette and placed in the automated soil particle size analyzer to acquire the particle size distribution. For each soil management system, three measurements were gathered with the aid of QUALISOLO software (Vaz et al., 2007), and soil texture was obtained for each system (Table 1).

$\mu_{\mathrm{m}}=\frac{\mu}{\rho}$

where $\mu$ is the linear attenuation coefficient, and $\rho\left(\mathrm{kg} \mathrm{m}^{-3}\right)$ is the physical density of the material. 
Table 1

Granulometric percentage and textural class for group I and II management types.

\begin{tabular}{|c|c|c|c|c|c|c|}
\hline Granulometric (\%) & $\begin{array}{l}\text { Soil from Native Forest } \\
\text { (NF) }\end{array}$ & Recuperated Soil (RS) & Recuperating Soil (G) & Degraded Soil (D) & $\begin{array}{l}\text { Recuperating Pasture Soil } \\
\text { (RP) }\end{array}$ & $\begin{array}{l}\text { Degraded Pasture Soil } \\
\text { (DP) }\end{array}$ \\
\hline Clay & 40 & 41 & 37 & 45 & 24 & 18 \\
\hline Silt & 8 & 7 & 7 & 5 & 3 & 3 \\
\hline Sand & 52 & 52 & 56 & 50 & 73 & 79 \\
\hline Textural Class & Sandy Clay & Sandy Clay & Sandy Clay & Sandy Clay & Sandy Clay Loam & Sandy Loam \\
\hline
\end{tabular}

\subsubsection{Microtomography calibration and image processing}

High-resolution microtomography was used for acquiring and reconstructing tomographic images. Initially, tomographic projections were obtained using an energy source with $100 \mathrm{kV}$, a current of $100 \mu \mathrm{A}$, and an $\mathrm{Al}$ and $\mathrm{Cu}$ filter, which were preselected specifications for undisturbed soil samples and diverse known materials. By definition, there is a linear relationship between the Hounsfield Unit (HU) and the linear attenuation coefficient (Crestana et al., 1985). Thus, we measured and established an X-ray microtomography calibration curve (model 1172 Skyscan (Belgium)) through image processing by using the manufacturer's software (CT-Analyzer). This step ensured equipment performance for image processing and soil geometric characteristic measurements (Fig. 1).

The projections were then acquired with a total rotation of $360^{\circ}$ in steps of $0.3^{\circ}$ and with a spatial resolution of $5 \mu \mathrm{m}$, as suggested by Vaz et al. (2011). Subsequently, the projections were reconstructed as bidimensional images with NRCon software (NRCon User Manual, 2011) with smoothing 5, ring artifact correction 10 , and beam hardening correction $60 \%$ (Fig. 2a-f).

\subsubsection{CHNS/O elemental analyzer}

A CHNS/O elemental analyzer was used to determine the soil C content. Initially, approximately $10 \mathrm{~g}$ of a soil sample was sieved (100 mesh) and encapsulated with tin foil to accelerate the analysis process. Two samples were analyzed for each type of soil management. The samples were combusted in a pure oxygen environment, and the resultant combustion gases were measured in an automated fashion.
Finally, all of the results were based on the known standard value of acetanilide, which has a well-known organic pattern and an elementary composition.

\subsubsection{Laser induced fluorescence spectroscopy (LIFS)}

LIFS was used to evaluate the humification degree of soil organic matter (SOM). First, soil samples were homogenized by milling with nitrogen gas to preserve soil properties. Then, $280 \mathrm{mg}$ soil samples were mixed with $120 \mathrm{mg}$ boric acid to ensure agglomeration between soil particles. Subsequently, the samples were pressed into a $0.5 \mathrm{~g}$ tablet with a thickness of $2 \mathrm{~mm}$ and a diameter of $10 \mathrm{~mm}$. The LIFS system consisted of a diode laser with a wavelength of $405 \mathrm{~nm}$ coupled to an optical bundle with 6 optical fibers to excite the soil sample and one central optical fiber to collect fluorescence signals from the sample. The spectrometer was a UV-vis USB2000 manufactured by Ocean Optics (Dunedin, FL, USA) with $500 \mathrm{~ms}$ of integration time and 5 boxcars. Each management option consisted of 4 repetitions.

\subsection{Physical analysis methods and software}

\subsubsection{Classical - porosity $\left(\phi_{c}\right)$}

Initially, the preselected samples were oven-dried and impregnated with paraffin wax. Based on Archimedes' principle, when an object $\left(\mathrm{m}_{\mathrm{s}}\right)$ is submerged in a liquid with known density, in this case is water $\left(\rho_{\mathrm{w}}=1 \mathrm{~g} / \mathrm{cm}^{3}\right)$, the displaced volume of liquid $\left(V_{1}\right)$ is equal to the object volume. We used this principle to calculate soil bulk density $\left(\rho_{\mathrm{b}}\right)$ (Eq. 2). With the QUALISOLO software, we empirically obtained the

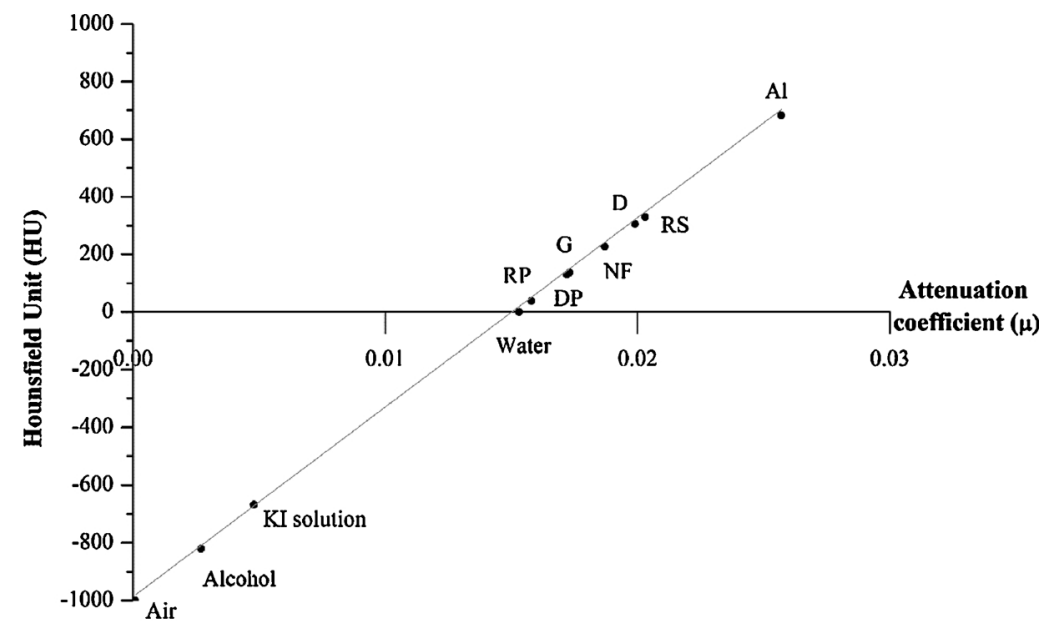

\begin{tabular}{|c|c|c|c|c|c|}
\hline $\begin{array}{l}\cdot \text { Al-Aluminium } \\
\text { - Alcohol } \\
\text { - Air } \\
\text { - KI solution - Potassium } \\
\text { Iodide solution ( } 1 \%) \\
\text { - NF - Soil from native } \\
\text { forest }\end{array}$ & $\begin{array}{l}\text { - } \mathbf{G}-\text { Regenerating soil } \\
\text { - } \mathbf{R S - R e g e n e r a t e d ~ s o i l ~} \\
\text { - D-Degraded soil } \\
\text { - } \mathbf{R P}-\text { Regenerating pasture } \\
\text { soil } \\
\text { - } \mathbf{D P}-\text { Degraded pasture soil }\end{array}$ & \begin{tabular}{|l|} 
Equation \\
Weight \\
Residual Sum \\
of Squares \\
Pearson's \\
Adj. R-Square \\
C \\
c \\
\end{tabular} & $\begin{array}{r}y=a+b^{*} x \\
\text { No Weighting } \\
19410.12419 \\
\quad 0.99709 \\
0.99354 \\
\text { Intercept } \\
\text { Slope }\end{array}$ & $\begin{array}{l}\text { Value } \\
-986.92985 \\
65747.98029 \\
\end{array}$ & $\begin{array}{r}\text { Standard Error } \\
26.2846 \\
1675.95625 \\
\end{array}$ \\
\hline
\end{tabular}

Fig. 1. Calibration curve of undisturbed soil samples and different materials. 


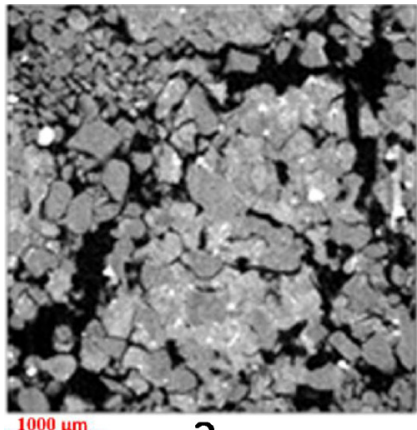

a

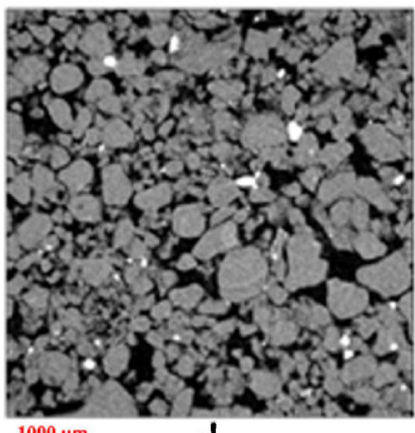

d

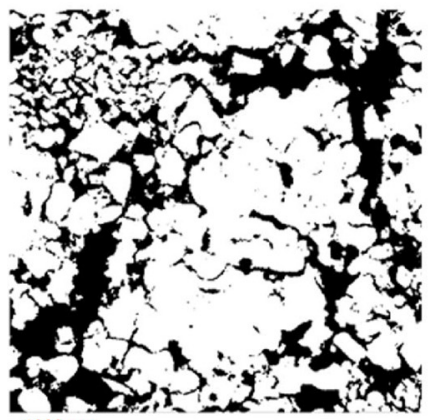

a

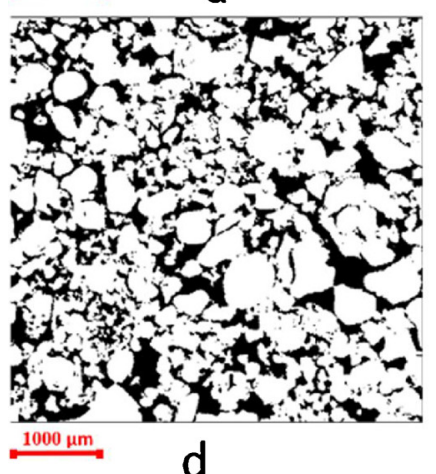

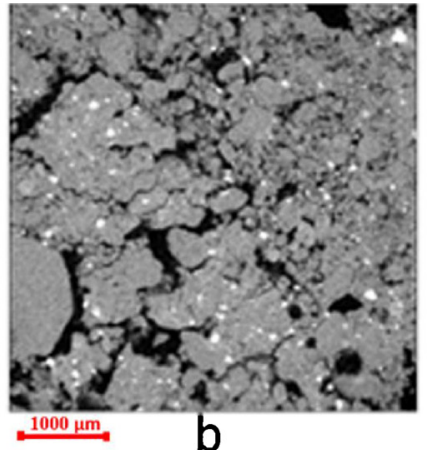

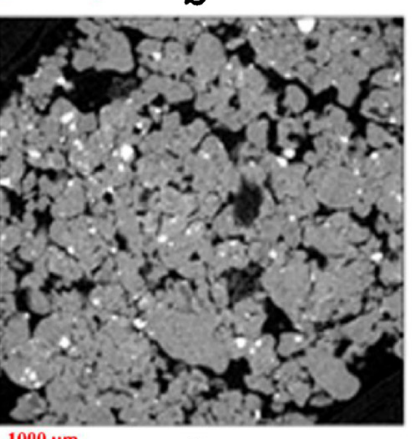

e

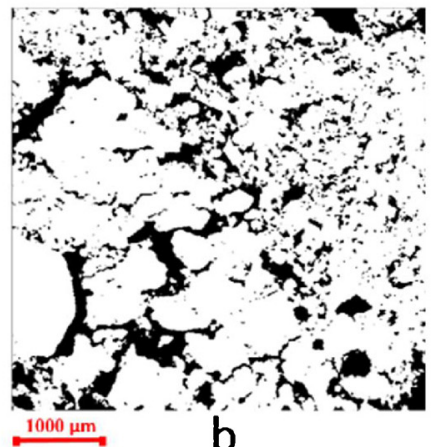

$1000 \mu \mathrm{m}$

b

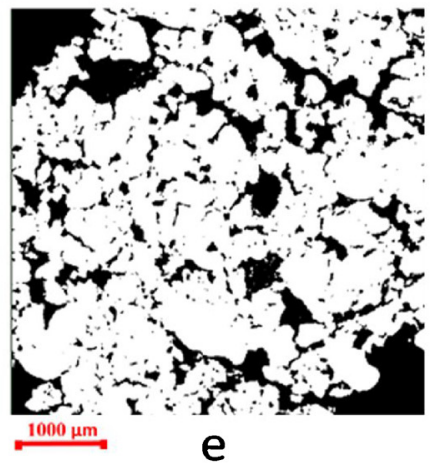

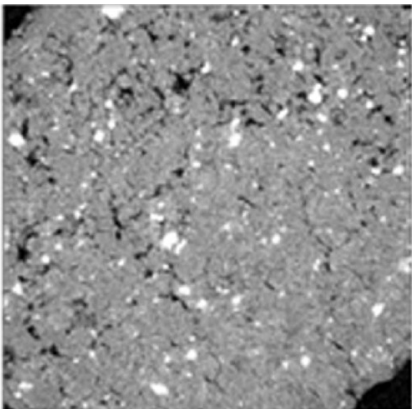

$1000 \mu \mathrm{m}, \quad$ C
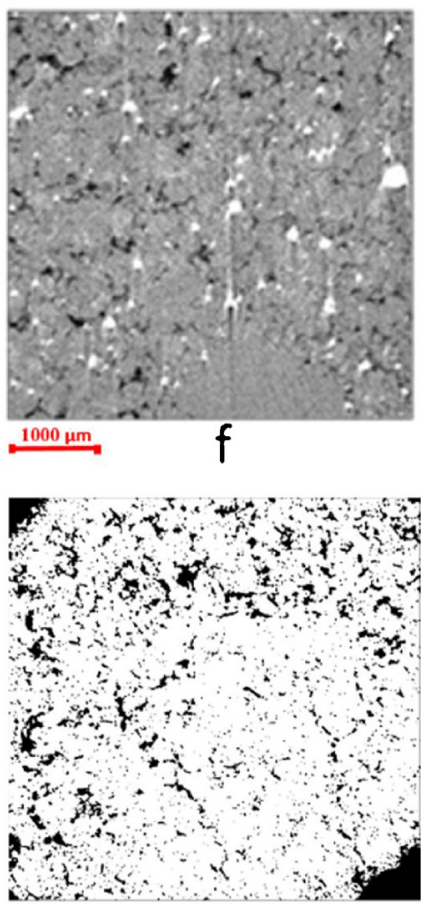

$1000 \mathrm{\mu m}, \quad \mathrm{C}$

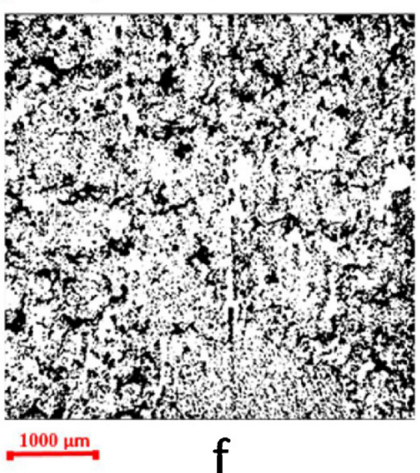

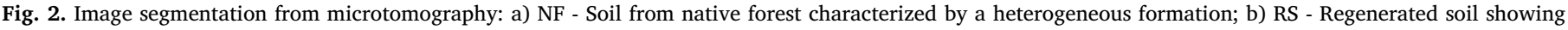

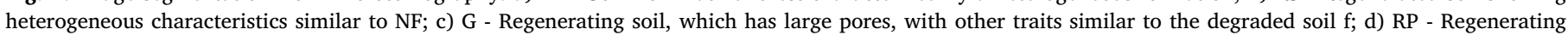

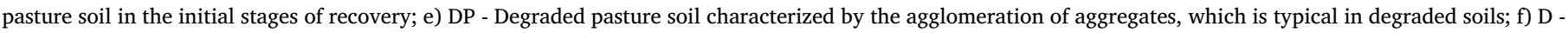
Degraded soil with a homogeneous profile that is characteristic of high compaction.

Table 2

Classification of pore shape (Skvortsova, 2009).

\begin{tabular}{|c|c|c|c|c|c|}
\hline Form factor interval & $\leq 0.20$ & $0.21-0.4$ & $0.41-0.6$ & $0.61-0.8$ & $0.81-1$ \\
\hline Pore Classification & Fissures & Elongated dissected & Isometric dissected & Isometric slightly dissected & Rounded \\
\hline Type of the structural organization & $\begin{array}{l}\text { Angular block } \\
\text { structure }\end{array}$ & $\begin{array}{l}\text { Angular block } \\
\text { structure }\end{array}$ & Crumb structure & $\begin{array}{l}\text { Massive (not separated into } \\
\text { aggregates) }\end{array}$ & $\begin{array}{l}\text { Massive (not separated into } \\
\text { aggregates) }\end{array}$ \\
\hline
\end{tabular}




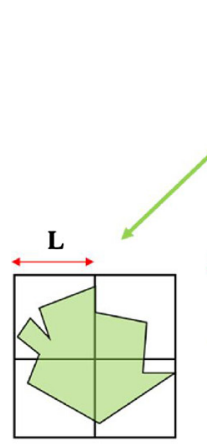

$\mathrm{n}\left(\mathrm{L}_{1}\right)$

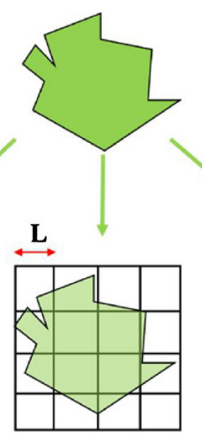

$\mathrm{n}\left(\mathrm{L}_{2}\right)$

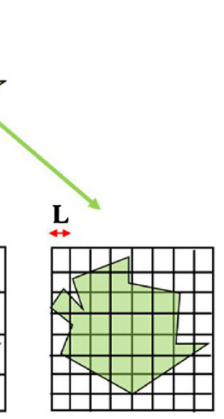

$\mathrm{n}\left(\mathrm{L}_{3}\right)$

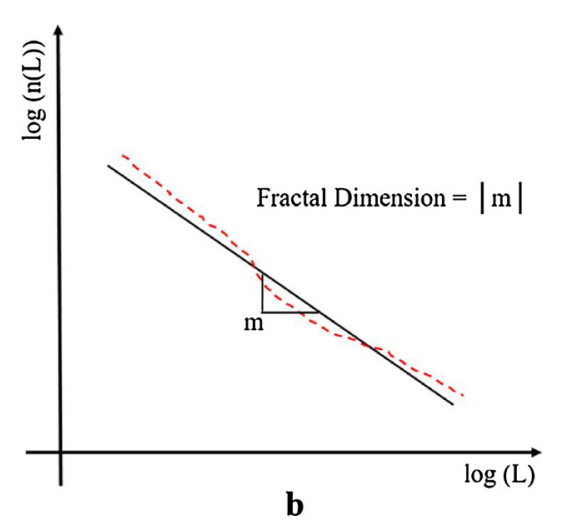

Fig. 3. a) The box-counting method applied in a theoretical fractal set (L) and b) the box number (n(L)) that is part of the fractal set (L) was plotted against the size of the box (L). The fractal dimension (D) is equal to the slope of the straight fitted line. Modified from Pascua et al. (2003).

Table 3

Pore classification (Brewer, 1964 and SSSA, 2008).

\begin{tabular}{lll}
\hline Class & Subclass & Effective Diameter $(\mu \mathrm{m})$ \\
\hline Macropores & Coarse & $>5000$ \\
& Medium & $2000-5000$ \\
& Fine & $1000-2000$ \\
Mesopores & Very fine & $75-1000$ \\
Micropores & & $35-75$ \\
Ultramicropores & & $5-30$ \\
Cryptopores & & $0.1-5$ \\
& & $<0.1$ \\
\hline
\end{tabular}

particle density ( $\rho_{\mathrm{p}}$ ) (Eq. 3) (Vaz et al., 2007 and Naime and Vaz, 2007). After measuring $\rho_{\mathrm{b}}$ and $\rho_{\mathrm{p}}$, Eq. (3) was used to obtain the total porosity of the soil $\left(\phi_{c}\right)$ (Eq. 4).

$\rho_{\mathrm{b}}=\rho_{\mathrm{w}} \frac{\mathrm{m}_{\mathrm{s}}}{\mathrm{V}_{\mathrm{l}}}$

$\rho_{\mathrm{p}}=2.026+2.325 \times \mu_{\mathrm{m}}$

$\phi_{\mathrm{c}}=1-\left(\frac{\rho_{\mathrm{b}}}{\rho_{\mathrm{p}}}\right)$

\subsubsection{CT analyzer - porosity $\left(\phi_{t}\right)$}

First, the reconstructed microtomographic image was binarized using the Otsu (1975) method (Manual for Bruker-micro CT - CT Analyzer, 2013), which consists of automatic selection of the optimum thresholds that minimize the between-class variances in the ROI (Region of Interest) of the images from the manufacturer's software CT Analyzer. Subsequently, the 2D porosity value was calculated slice-byslice, by dividing the empty space by the total area, including the empty space for each of the image slices. Finally, the 3D porosity was obtained by integrating the porosity measured over all 500 images.

\subsubsection{ImageJ - shape factor}

ImageJ is a public domain image processing program that was developed by the NIH (National Institutes of Health) and has more than 500 plugins available (Schneider et al., 2012).

The shape factor provides information about the geometric structure organization and can be used to determine the degree of soil degradation. Skvortsova (2009) suggested the following shape factor formula (Eq. 5) for calculating pore shape:

$\mathrm{F}=\left(\frac{4 \pi \mathrm{S}}{\mathrm{P}^{2}}+\frac{\mathrm{D}}{\mathrm{L}}\right) / 2$

In this equation, $\mathrm{S}$ is the area, $\mathrm{P}$ is the perimeter, and $\mathrm{D}$ and $\mathrm{L}$ are the transversal and longitudinal linear dimensions, respectively (Karsanina et al., 2015). These values were acquired from ImageJ's command Analyze Particles, which considered D as the minor axis and $\mathrm{L}$ as the major axis of the selected object in a binary image.

Once the values of the shape factors are obtained, they are separated into five classes based on pore shape and three types of structural organization, as seen in Table 2 of Skvortsova (2009). Due to the large amount of information contained in a single microtomographic image and considering digital processing time, one layer of the middle section from 500 bidimensional images was used in this study to show the potential of this parameter for analyzing different soil structures.

\subsubsection{CT analyzer - fractal dimension}

At first, the ROI was selected from the image and binarized by using the Otsu (1975) method; next, the 2D fractal dimension was calculated by covering the structure with boxes of length $r$ (i.e., the Kolmogorov or "box-counting" method). The image was divided into an array of equally sized squares that contained part of the object surface, and this procedure was repeated over a range of box sizes. The number of boxes that contained surface was plotted against box length in a log-log plot. Finally, the fractal dimension was calculated from the slope of the loglog regression (Fig. 3).

\subsubsection{ImageJ - lacunarity}

For the present study, the open plugin FracLac developed by the University of Charles Sturt, Australia, was used under the ImageJ environment (Karperien, 2007). This plugin was implemented to measure the lacunarity of the microtomographic image. The FracLac algorithm was used to calculate the lacunarity using a measure of pixel intensity for different sizes of "Gliding boxes" (Allain and Cloitre, 1991). FracLac uses the first moments Z(1) and Z(2) defined by Plotnick et al. (1996) as a function of the mean of measurements $(\tau)$ and their standard deviation (ơ), which vary with the length of the box (b) and the width of the

Table 4

Porosity obtained by classical $\left(\phi_{\mathrm{c}}\right)$ and microtomographic $\left(\phi_{\mathrm{t}}\right)$ methods (\%) with a voxel of $5 \mu \mathrm{m} \times 5 \mu \mathrm{m} \times 5 \mu \mathrm{m}$ for group I and II.

\begin{tabular}{|c|c|c|c|c|c|c|}
\hline Type of management & NF & RS & G & $\mathrm{D}$ & $\mathrm{RP}$ & DP \\
\hline Total porosity $\left(\phi_{c}\right)$ in this study (\%) & $55.4 \pm 0.1$ & $47.3 \pm 0.3$ & $42.2 \pm 0.1$ & $41.7 \pm 0.1$ & $39.6 \pm 0.2$ & $41.7 \pm 0.3$ \\
\hline Macroporosity $\left(\phi_{t}\right)(\%)$ & $31.9 \pm 1.5$ & $24.7 \pm 4.4$ & $41.8 \pm 2.6$ & $37.3 \pm 1.9$ & $32.1 \pm 2.3$ & $21.6 \pm 2.6$ \\
\hline Microporosity $\left(\phi_{\mathrm{c}}-\phi_{\mathrm{t}}\right)(\%)$ & $23.5 \pm 1.6$ & $22.6 \pm 4.3$ & $0.3 \pm 2.7$ & $4.4 \pm 2.0$ & $7.5 \pm 2.5$ & $20.1 \pm 2.9$ \\
\hline
\end{tabular}


Table 5

Carbon content and degree of humification for group I and II.

\begin{tabular}{|c|c|c|c|c|c|c|}
\hline Type of management & $\mathrm{NF}$ & RS & G & $\mathrm{D}$ & $\mathrm{RP}$ & DP \\
\hline C content $(\%)$ & $1.66^{\mathrm{a}}$ & $1.22^{\mathrm{a}}$ & $0.72^{\mathrm{a}}$ & $0.19^{\mathrm{a}}$ & $0.58^{\mathrm{a}}$ & $0.85^{\mathrm{a}}$ \\
\hline Humification index (a.u.) & $3.95 \pm 0.33$ & $5.06 \pm 0.19$ & $8.88 \pm 0.66$ & $35.52 \pm 3.07$ & $10.70 \pm 0.71$ & $7.74 \pm 0.43$ \\
\hline
\end{tabular}

a.u.: Arbitrary units.

a Standard deviation: Lower than the limit of detection of the reference techniques.
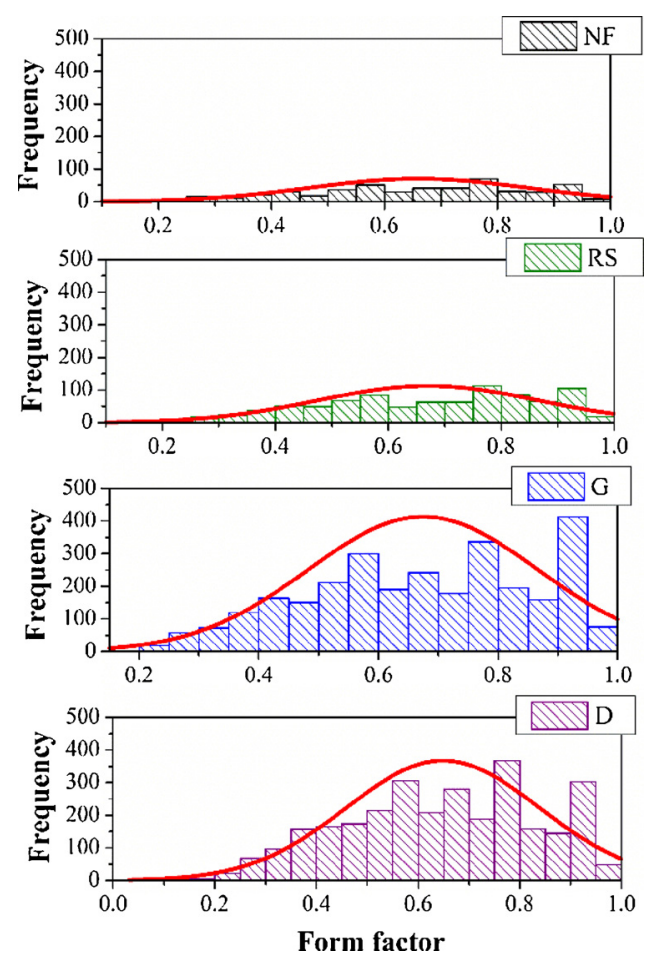

Fig. 4. Form factor obtained by using the classification method of Skvortsova (2009) - Group I.

image (T) given in number of pixels; the condition is always $\mathrm{b} \leq \mathrm{T}(6)$ and (7).

$Z(1)=\tau$

$\mathrm{Z}(2)=O^{2}+\tau^{2}$

By definition, the lacunarity equation $(\Lambda(r))$ is a straight correlation between functions Z (1) and Z (2), which is represented by Eqs. (8) and (9).

$\Lambda(\mathrm{r})=\frac{Z(2)}{[Z(1)]^{2}}$

$\Lambda(\mathrm{r})=\frac{o^{2}}{\tau^{2}}+1$

The ratio between ơ and $\tau$ changes according to the varying size of the "Gliding box" (r). That is, the lacunarity value depends on the scale of the "Gliding box" over the image. Based on Eq. (9), a log-log plot of lacunarity versus the size of the "Gliding box" on the x-axis was produced. One representative bidimensional image was selected from each sample to calculate the lacunarity value.

\subsubsection{Humification index}

According to Milori et al. (2006), the humification index $\left(\mathrm{H}_{\mathrm{FIL}}\right)$ is defined by Eq. (10), where $A_{f}$ is the florescence area and $C_{T}$ is the total carbon content determined by elemental analysis.

$$
H_{F I L}=\frac{A_{f}}{C_{T}}
$$

\section{Results and discussion}

\subsection{Porosity $-\phi_{c}$ and $\phi_{t}$}

The pore size distribution is directly related to the water drainage and retention capacity of the soil as well as the soil aeration conditions. Currently, benchtop or cabinet-type scanners allow us to obtain a resolution of approximately $1-100 \mu \mathrm{m}$ for samples ranging from a few millimeters to a few centimeters in diameter (Cnudde and Boone, 2013; Vaz et al., 2011).

Due to tomography constraints, we considered pores detectable by microtomography with a diameter greater than $10 \mu \mathrm{m}$, which is consistent with the preselected resolution. This range of resolution is sufficient to detect macropores, mesopores and some micropores (Table 3). Clearly, this spatial resolution is ideal for studying macropores, as verified by the evaluation of porosity under three systems of management by Beraldo et al. (2014). This procedure highlights that, in this case, a comparison of the effective porosity percentages obtained with two different methods of analysis for each of the different management systems is possible on a micrometric scale.

According to Marchini et al. (2015) and Bonini and Alves (2011), who investigated the same soils that were considered in this study through use of classical methods, we verified that both methods have the same order of magnitude, i.e., the adopted resolution in this study was pertinent to investigate soil geometrical properties. Once the detectable pore resolution was verified, we estimated the microporosity by calculating $\phi_{\mathrm{c}}-\phi_{\mathrm{t}}$.

Group I (Table 4): Based on consistent in situ field conditions, we first obtained the total porosity percentage using the classical method. NF showed the highest measured value, followed by RS and then G and $\mathrm{D}$ (similar values). This finding corresponded with the result obtained by Marchini et al. (2015), including the same order observed in C content (i.e., the quantity of macroaggregates) and the reverse order in the humification index (Table 5), which indicates how soil organic matter is protected inside aggregates. However, an unexpected result was verified by the tomographic method: G showed the largest macroporosity, followed by $\mathrm{D}, \mathrm{NF}$, and RS. We presumed that RS was able to recover part of its macropore and microporosity proportion because its total porosity was closer to that of NF and because D should present cracks at the vertical axis. G did not show any notable variations between the two methods for two reasons: i) the presence of sewage sludge should contribute to the soil aggregate stability and pore formation ii) the decompression effect caused by the native tree species Gonçalo-Alves (Astronium fraxinifolium) was the only factor favoring the formation of large pores with a physical structure similar to that of degraded soil. Then, when comparing this result with the result from the classical method, we indirectly estimated the quantity of micropores at this resolution.

Group II (Table 4): Based on the established spatial resolution and threshold, (i.e., detectable porosity), NF and DP had the highest total porosity, and RP had the lowest total porosity. However, RP had a higher macroporosity than DP, which is an excellent signal of ongoing recovery processes. This difference can therefore be stated as follows: 

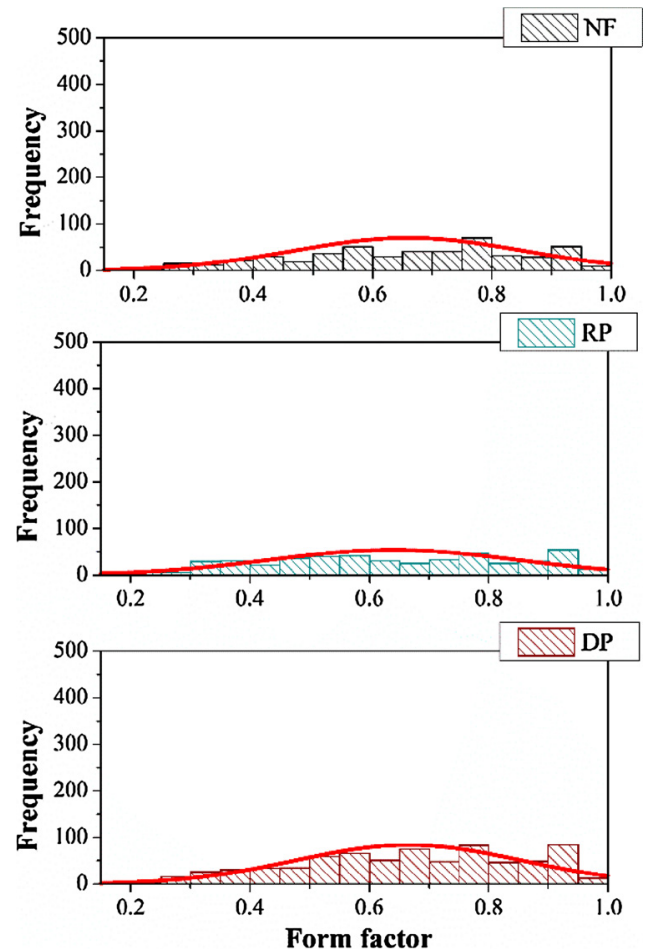

Fig. 5. Form factor obtained by using the classification method of Skvortsova (2009) - Group II.

for RP, the soil was aerated during preparation, leading to greater infiltration, soil moisture content and consequently, microbial activity, i.e., in a certain time period, the $\mathrm{C}$ content decreased and the degree of humification increased (Alves and Menezes de Souza, 2008). Consequently, the soil chemical conditions deteriorated (Table 5), and the lowest total porosity was measured. Meanwhile, DP was in an equilibrium state. Additionally, DP contained more micropores below the established resolution than RP. One sign of degradation is reflected in soil compaction, with decreased macroporosity and increased microporosity (de Andrade Bonetti et al., 2017). Furthermore, an increase in soil OM can reduce the resistance of the soil to compaction, as shown by the close RP and NF macroporosity values; thus, it was concluded that the soil structural recovery process was effective.

\subsection{Shape factor}

Soil pore characteristics are essential for soil strength and fragmentation (Munkholm et al., 2002). Thus, to understand more about soil pore characteristics following the classification system of Skvortsova (2009), the stages of soil structure degradation are as follows: granular (crumb) structure, blocky structure, platy structure (predominantly in a horizontal direction), massive soil structure (nonaggregated soil), and finally, a structure that acquires the characteristics of its parent material. Therefore, the geometric structures of the soils from the different managements were evaluated (Figs. 4 and 5) and are presented in a histogram.

Group I (Fig. 4 and Table 6): As shown in the G and D histograms, these soils are at an advanced stage of degradation at the pore scale, with high shape factor values of between 0.61 and 1.0. That is, these soils have massive structure and acquired typical aspects from their original material. The shape factors observed for G and D were higher than those observed for RS and NF. Additionally, the structure of RS improved, becoming closer to the structure of NF, whereas the structural-geometric characteristics of $\mathrm{G}$ and $\mathrm{D}$ were lost. The average of the detected NF and RS pore shapes was low, thereby representing the quality of natural soil, while D and G contained high, isometric, slightly dissected and rounded pores at predominant intervals, indicating greater uniformity and fragmentation and characterizing their stages of degradation.

Group II (Fig. 5 and Table 6): The average soil pore shape factor for the two pastures indicated slightly isometric and dissected pores. By separately analyzing the pore size histograms from the pastures, RP was found to have a lower value than NF, thereby highlighting the positive impact of the regeneration of its structure.

Therefore, the Skvortsova (2009) classification was relevant and valid for the tropical soil in this study; however, it is still necessary to conduct more experiments in order to validate and generalize this classification method for tropical soils.

\subsection{Fractal dimension}

The fractal dimension was used to characterize the degree of roughness or irregularity of the soil surface, i.e., soil particle-aggregates-size distribution (Uthayakumar et al., 2011). However, this distribution is usually calculated as a cumulative function based on power law relations and its exponents and is interpreted as a fractal dimension (Bittelli et al., 1999).

Group I (Table 7): The fractal dimension ascending order is G, D, NF and RS, which indicated that the soil texture (Table 1) and the fractal dimension might be related to each other. The fractal dimension can increase with the clay content, as shown in NF and RS, which have the same sand content. The fractal dimension can also decrease with sand content, as shown in G and D (Bittelli et al., 1999).

Group II (Table 7): The ascending order for this group is RP, NF and DP. For RP and NF, the clay content is the dominant factor for the fractal dimension, while for DP, the sand content is the dominant factor (Table 1).

The fractal dimension was successfully used to characterize the soil particle and aggregate size distribution but was not sufficient for describing the soil geometry properties when used alone. Thus, another parameter, the lacunarity, must be coupled with the fractal dimension to better represent soil structural characteristics.

\subsection{Lacunarity}

Lacunarity is a counterpart of the fractal dimension that describes the textural elements of the fractal; however, sometimes soils with the same fractal dimension can rest in a totally different geometric arrangement (Monreal et al., 2013). Thus, the application of lacunarity in combination with fractal dimension in the analysis of soils provides a powerful tool that can be used to obtain important information about the soil physical properties and transport phenomena. Roy and Perfect (2014) demonstrated lacunarity as a single number that takes into account the clustering of pixels in a pattern at different scales. Three main shapes were used to characterize the log-log lacunarity: linear, concave and sigmoidal.

Table 6

Shape factor obtained by microtomography for group I and II.

\begin{tabular}{|c|c|c|c|c|c|c|}
\hline Type of Management & $\begin{array}{l}\text { Soil from Native Forest } \\
\text { (NF) }\end{array}$ & Recuperated Soil (RS) & Recuperating Soil (G) & Degraded Soil (D) & $\begin{array}{l}\text { Recuperating Pasture Soil } \\
\text { (RP) }\end{array}$ & $\begin{array}{l}\text { Degraded Pasture Soil } \\
\text { (DP) }\end{array}$ \\
\hline Shape factor & 0.79 & 0.77 & 0.82 & 0.80 & 0.72 & 0.75 \\
\hline
\end{tabular}


Table 7

Fractal dimensions of group I and II.

\begin{tabular}{|c|c|c|c|c|c|c|}
\hline Type of Management & $\begin{array}{l}\text { Soil from Native Forest } \\
\text { (NF) }\end{array}$ & Recuperated Soil (RS) & Recuperating Soil (G) & Degraded Soil (D) & $\begin{array}{l}\text { Recuperating Pasture Soil } \\
\text { (RP) }\end{array}$ & $\begin{array}{l}\text { Degraded Pasture Soil } \\
\text { (DP) }\end{array}$ \\
\hline Fractal Dimension & 1.88 & 1.91 & 1.78 & 1.82 & 1.87 & 1.91 \\
\hline
\end{tabular}

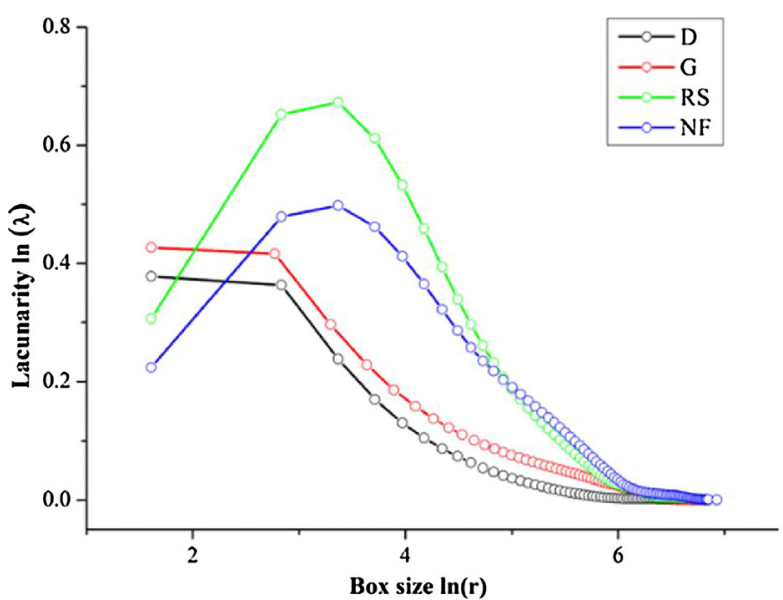

a)

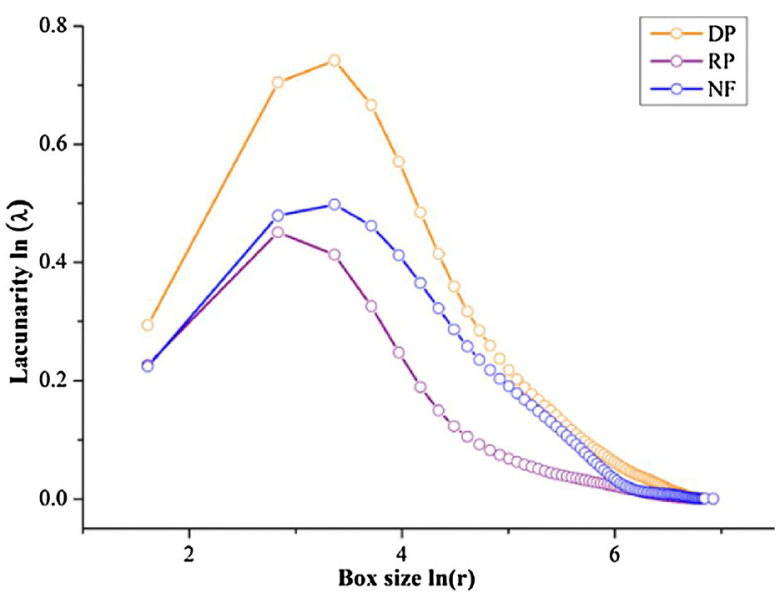

b)

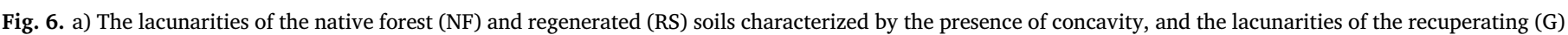

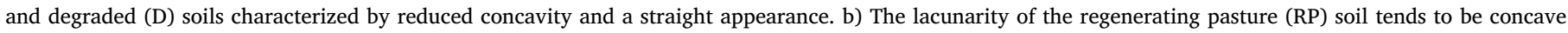
because the lacunarities of the NF and degraded pasture (DP) soils are also concave.

Table 8

Lacunarity of group I and II.

\begin{tabular}{|c|c|c|c|c|c|c|}
\hline Type of Management & $\begin{array}{l}\text { Soil from Native Forest } \\
\text { (NF) }\end{array}$ & Recuperated Soil (RS) & Recuperating Soil (G) & Degraded Soil (D) & $\begin{array}{l}\text { Recuperating Pasture Soil } \\
\text { (RP) }\end{array}$ & $\begin{array}{l}\text { Degraded Pasture Soil } \\
\text { (DP) }\end{array}$ \\
\hline Lacunarity & 0.09 & 0.11 & 0.05 & 0.03 & 0.05 & 0.14 \\
\hline
\end{tabular}

In fact, taking into account the results obtained by FractaLac, the relationship between occupied sets and lacunarity was inversely proportional. For the same box size, the lacunarity decayed when the degree of compaction increased or the pore continuity was ruptured.

Group I (Fig. 6a and Table 8): The curve tends to form a concave downward curve in NF and RS. This shape represents a soil structure that is highly clustered with a single large gap in the middle, indicating that the textural patterns are composed of clumped data and have high lacunarity. In contrast, the second curve of a degraded soil (D) and recuperating soil (G) showed an increasing degree of compaction while under management, and the curve tended to straighten, which resembled fractal behavior.

When the total porosity in soil increases, the average lacunarity decreases. Therefore, the lacunarity is inversely proportional with porosity and is related to the pore distribution. The soils are listed in decreasing order by their set distribution (i.e., from the more homogeneous to heterogeneous): D, G, NF, and RS.

Group II (Fig. 6b and Table 8): It was observed that RP tends to regenerate concavity as $\mathrm{NF}$, and $\mathrm{DP}$ also shows concavity in the figure. However, when analyzing the lacunarity number of DP and considering its granulometry, it can be assumed that the concavity results from the effect of the high proportion of sand and the low proportion of clay, which forms the large set distribution detectable at the microtomograph resolution.

Additionally, lacunarity is helpful for determining object self-similarity existence, and the REV is used for porous media. When the $r$ value approaches the REV, the lacunarity decreases to zero and remains constant (Luo and Lin, 2009). We observed that $\ln [\mathrm{L}(\mathrm{r})]=0$ when $r>6.5$ for all types of management in this study. Thus, although all management scenarios are not represented in this study, the adopted spatial resolution of $5 \mu \mathrm{m}$ is acceptable with respect to the previous condition $r>6.5$

\section{Conclusion}

The methods used in this study were successful for analyzing and distinguishing the structural statuses of soils at high accuracy. However, there are still limitations revealed by this study that should be taken into account and further addressed. For instance, microtomography was able to capture parts of the micropores and showed an excellent opportunity to identify meso- and macropores entirely. Additionally, although the shape factor was effective for pore class evaluation, it must be further validated for use in tropical soils. Furthermore, the fractal dimension is related to the particle and aggregate size distributions but cannot be used to characterize soil geometric features. However, soil geometric features can be determined by coupling the fractal dimension with the lacunarity parameter. In this study, the lacunarity parameter proved to be an important tool for estimating the soil structural status. Each type of soil structure had a random or fractal character related to the suitable or degraded condition of the soil. In addition, the lacunarity was related to the REV. Finally, the set of proposed unconventional methods and analytical tools used in this study were able to characterize and evaluate the geometric characteristics of different soil structures. Consequently, the results are promising in the sense that the approach employed here may be helpful for predicting the flow of water in soils with different 
structures.

\section{References}

Allain, C., Cloitre, M., 1991. Characterizing the lacunarity of random and deterministic fractal sets. Phys. Rev. A 44, 3552-3558.

Alves, M.C., Menezes de Souza, Z., 2008. Recuperação de área degradada por construção de hidroelétrica com adubação verde e corretivo. Revista Brasileira de Ciência do solo 32 (6).

Beraldo, J.M.G., Scannavino Junior, F.A., Cruvinel, P.E., 2014. Application of x-ray computed tomography in the evaluation of soil porosity in soil management systems. Eng. Agric. Jaboticabal 34, 1162-1174.

Bittelli, M., Campbell, G.S., Flury, M., 1999. Characterization of particle-size distribution in soils with a fragmentation model. Soil Sci. Soc. Am. J. 63 (4), 782-788.

Bonini, S.B., Alves, M.C., 2011. Recovery of soil physical properties by green manure, liming, gypsum and pasture and spontaneous native species ${ }^{1}$. Revista Brasileira de Ciência do Solo 35 (4), 1397-1406.

Brewer, R., 1964. Fabric and Mineral Analysis of Soils. Wiley, New York.

Carducci, C.E., Zinn, Y.L., Rossoni, D.F., Heck, R.J., Oliveira, G.C., 2016. Visual analysis and $\mathrm{x}$-ray computed tomography for assessing the spatial variability of soil structure in a cultivated oxisol. Soil Tillage Res.

Cnudde, V., Boone, M.N., 2013. High-resolution x-ray computed tomography in geosciences: a review of the current technology and applications. Earth Sci. Rev. 123, $1-17$.

Crestana, S., Mascarenhas, S., Pozzi-Mucelli, R.S., 1985. Statical and dynamical three dimensional studies of water in soil using computed tomography scanning. Soil Sci. 140, 326-332.

de Andrade Bonetti, J., Anghinoni, I., de Moraes, M.T., Fink, J.R., 2017. Resilience of soils with different texture, mineralogy and organic matter under long-term conservation systems. Soil Tillage Res. 174, 104-112.

Solos, Embrapa, 2013. Sistema brasileiro de classificação de solos, 3th ed. Centro Nacional de Pesquisa de Solos, Rio de Janeiro.

Karperien, A., 2007. FracLac for ImageJ-FracLac Advanced User's Manual. Charles Sturt University, Australia.

Karsanina, M.V., Gerke, K.M., Skvortsova, E.B., Mallants, D., 2015. Universal spatial correlation functions for describing and reconstructing soil microstructure. PloS One 10 (5), e0126515.

Luo, L., Lin, H., 2009. Lacunarity and fractal analyses of soil macropores and preferential transport using micro-x-ray computed tomography. Vadose Zone J. 8 (1), 233-241.

Manual for Bruker-micro CT - CT Analyser v. 1.13, 2013. http://bruker-microct.com/ next/CTan_UserManual.pdf (Accessed 28 June 2016).

Marchini, D.C., Ling, T.G.C., Alves, M.C., Crestana, S., Souto Filho, S.N., Arruda, O.G., 2015. Matéria orgânica, infiltração e imagens tomográficas de Latossolo em recuperação sob diferentes tipos de manejo. Rev. Bras. Eng. Agríc. Amb 19, 574-580.

Martínez, F.S.J., Caniego, F.J., García-Gutiérrez, C., 2017. Lacunarity of soil macropore space arrangement of CT images: effect of soil management and depth. Geoderma 287, 80-89.

Milori, D.M.B.P., Galeti, H.V.A., Martin-Neto, L., Dieckow, J., González-Pérez, M., Bayer, C., Salton, J., 2006. Organic matter study of whole soil samples using laser-induced fluorescence spectroscopy. Soil Sci. Soc. Am. J. 70 (1), 57-63.

Monreal, J.C., Martínez, F., Martí, J.J., Pérez-Gómez, R., 2013. Lacunarity of the spatial distributions of soil types in Europe. Vadose Zone J. 12 (3).

Munkholm, L.J., Heck, R.J., Deen, B., Zidar, T., 2016. Relationship between soil aggregate strength, shape and porosity for soils under different long-term management. Geoderma 268, 52-59.

Munkholm, L.J., Schjønning, P., Kay, B.D., 2002. Tensile strength of soil cores in relation to aggregate strength, soil fragmentation and pore characteristics. Soil Tillage Res. 64 (1-2), 125-135.
Naime, J.D.M., Vaz, C., 2007. Estudo e implementação de modelo mais preciso para determinação da granulometria do solo por atenuação de raios gama. Embrapa Instrumentação Agropecuária-Boletim de Pesquisa e Desenvolvimento (INFOTECA-E)

Naime, J.M., Vaz, C.M.P., Macedo, A., 2001. Automated soil particle size analyzer based on gamma-ray attenuation. Comput. Electron. Agric. 31 (3), 295-304.

Naveed, M., Schjønning, P., Keller, T., de Jonge, L.W., Moldrup, P., Lamandé, M., 2016. Quantifying vertical stress transmission and compaction-induced soil structure using sensor mat and x-ray computed tomography. Soil Tillage Res. 158, 110-122.

NRCon User Manual, 2011, http://bruker-microct.com/next/NReconUserGuide.pdf (accessed 28.06.16)

Otsu, N., 1975. A threshold selection method from gray-level histograms. Automatica 11, 23-27.

Pascua, M.R., De Vicente, G., Calvo, J.P., Pérez-López, R., 2003. Similarities between recent seismic activity and paleoseismites during the late miocene in the external Betic Chain (Spain): relationship by 'b'value and the fractal dimension. J. Struct. Geol. 25 (5), 749-763.

Passoni, S., Borges, F.D.S., Pires, L.F., Saab, S.D.C., Cooper, M., 2014. Software image J to study soil pore distribution. Ciência e Agrotecnologia 38, 122-128.

Perfect, E., Kay, B.D., 1995. Applications of fractals in soil and tillage research: a review. Soil Tillage Res. 36 (1-2), 1-20.

Pires, L.F., Borges, J.A., Rosa, J.A., Cooper, M., Heck, R.J., Passoni, S., Roque, W.L., 2017. Soil structure changes induced by tillage systems. Soil Tillage Res. 165, 66-79.

Plotnick, R.E., Gardner, R.H., Hargrove, W.W., Prestegaard, K., Perlmutter, M., 1996. Lacunarity analysis: a general technique for the analysis of spatial patterns. Phys. Rev. E 53, 5461.

Reynolds, W.D., Drury, C.F., Tan, C.S., Fox, C.A., Yang, X.M., 2009. Use of indicators and pore volume-function characteristics to quantify soil physical quality. Geoderma 152, 252-263. http://dx.doi.org/10.1016/j.geoderma.2009.06.009.

Roy, A., Perfect, E., 2014. Lacunarity analyses of multifractal and natural grayscale patterns. Fractals 22 (03), 1440003.

Schneider, C.A., Rasband, W.S., Eliceiri, K.W., 2012. NIH image to imageJ: 25 years of image analysis. Nat. Methods 9 (7), 671-675.

Senesi, G.S., Martin-Neto, L., Villas-Boas, P.R., Nicolodelli, G., Milori, D.M., 2016. Laserbased spectroscopic methods to evaluate the humification degree of soil organic matter in whole soils: a review. J. Soils Sediments 1-11.

Six, J., Paustian, K., Elliott, E.T., Combrink, C., 2000. Soil structure and organic matter I. Distribution of aggregate-size classes and aggregate-associated carbon. Soil Sci. Soc. Am. J. 64 (2), 681-689.

Skvortsova, E.B., 2009. Changes in the geometric structure of pores and aggregates as indicators of the structural degradation of cultivated soils. Euras. Soil Sci. 42, 1254-1262.

Soil Science Society of America, 2008. Glossary of soil science terms 2008. ASA-CSSASSSA.

Tseng, C.L., Alves, M.C., Crestana, S., 2018. Quantifying physical and structural soil properties using x-ray microtomography. Geoderma 318, 78-87.

Uthayakumar, R., Prabakar, G.A., Azis, S.A., 2011. Fractal analysis of soil pore variability with two dimensional binary images. Fractals 19 (04), 401-406.

Vaz, C.M.P., Oliveira, J.C.M., Reichardt, K., 1992. Soil mechanical analysis through gamma ray attenuation. SMR 705, 24.

Vaz, C.M., De Maria, I.C., Lasso, P.O., Tuller, M., 2011. Evaluation of an advanced benchtop micro-computed tomography system for quantifying porosities and poresize distributions of two Brazilian Oxisols. Soil Sci. Soc. Am. J. 75, 832-841.

Vaz, C., Naime, J.D.M., da Silva, A.M., Rabello, L., Crestana, S., Cruvinel, P., 2007. Equipamentos e métodos para análise física dos solos. Embrapa InstrumentaçãoCapítulo em livro técnico-científico (ALICE).

Zeng, Y., Payton, R.L., Gantzer, C.J., Anderson, S.H., 1996. Fractal dimension and lacunarity of bulk density determined with x-ray computed tomography. Soil Sci. Soc. Am. J. 60 (6), 1718-1724. 